\title{
Categorías migratorias en México. Análisis a la Ley de Migración*
}

\author{
Migratory Categories in Mexico. \\ Analysis of the Migration Act
}

\section{Luisa Gabriela Morales Vega**}

Sumario: I. Introducción. II. Ley de Migración. III. Disposiciones relevantes. IV. Análisis comparativo con la Ley General de Población. V. Conclusiones. VI. Bibliografía.

* Artículo recibido el 6 de julio de 2011 y aprobado para publicación el 6 de octubre de 2011.

** Maestra y doctoranda en derecho por la FES Acatlán de la UNAM. Especialista en la consulta, orientación y gestión de trámites migratorios. Docente en las materias de Derecho Internacional y Derecho Civil. 
Resumen: La Ley de Migración expedida en 2011, deroga las disposiciones que en materia migratoria contempla la Ley General de Población, y forma parte de una serie de reformas jurídicas implementadas por México como estrategia para gobernar los diversos procesos migratorios que concurren en el país. El presente artículo tiene por objeto presentar algunas reflexiones sobre los artículos relevantes que se incluyen en esta Ley de Migración, así como de las coincidencias y divergencias que la misma presenta con la Ley General de Población que ha regulado el fenómeno migratorio desde hace más de 30 años en México, a fin de determinar las ventajas y desventajas que su aplicación proporcionará a los migrantes.

Palabras clave: migración, migrante, derechos humanos, residente temporal, residente permanente.

ABSTRACT: The Migration Act issued in 2011, repeals the provisions relating to migration included in the Population General Act, and is part of a series of legal reforms implemented by Mexico as a strategy to rule the various migration processes which contribute to the country. This article aims to present some thoughts on relevant items included in the Migration Act, as well as the similarities and differences that it presents to the Population General Act migration has been regulated for more than 30 years in Mexico, to determine the advantages and disadvantages that your application will provide to migrants.

Descriptors: Migration, migrants, human rights, temporary resident, permanent resident.

RÉSUMÉ: La loi sur les migrations, publiée en 2011, abroge des dispositions relatives à la migration qui ont été comprises dans la loi générale sur la population, et celle est partie d'une série de réformes juridiques mises en cuvre par le Mexique comme une stratégie pour réguler les processus de migration qu'il y a dans le pays. Cet article vise à présenter quelques réflexions sur les articles plus importants inclus dans la loi sur les migrations, ainsi que les similitudes et les différences qu'elle présente avec la loi générale sur la population qui a été réglementé le phénomène depuis plus de 30 ans au Mexique, afin de déterminer les avantages et les inconvénients que votre demande sera de fournir aux migrants.

Mots-clés: migration, les migrants, les droits humains, le résident temporaire, le résident permanent. 


\section{INTRODUCCIÓN}

La creciente interacción estatal, facilitada por los avances en tecnología y comunicaciones, que se manifiesta en la tendencia mundial hacia un intercambio de bienes, servicios, información y capitales más libre, acarrea consecuentemente una intensa movilidad internacional de personas; por ello es que la migración internacional cobra protagonismo en la agenda política mundial actual. En Latinoamérica, el caso de México es relevante, al ser un país de origen, destino, tránsito y retorno de gran cantidad de migrantes $;^{1}$ consciente de esta realidad el Estado mexicano ha implementado recientemente modificaciones importantes en su política, tanto interior como exterior, como estrategia para enfrentar los retos que los grandes flujos migratorios, implican para la gobernabilidad del propio Estado. Estas estrategias van desde una actividad internacional más intensa, hasta, entre otras, la propuesta de creación de una fiscalía federal especializada en delitos contra migrantes, modificaciones a la legislación migratoria y la implementación de nuevos criterios para la admisión de extranjeros en México; acciones que revisten interés para otros Estados, principalmente centro y sudamericanos, puesto que los destinatarios de las mismas, son en su mayoría ciudadanos suyos. ${ }^{2}$

Entre las reformas legales realizadas ${ }^{3}$ se encuentran las diversas modificaciones y derogaciones a la Ley General de Población, que ahora únicamente norma la materia de población, la migración interna y parte de la emigración; ${ }^{4}$ asimismo la promulgación de la Ley sobre Refugia-

1 De acuerdo a los informes publicados por el Instituto Nacional de Migración, desde el 2009, aproximadamente 9 millones de personas cruzan las fronteras mexicanas anualmente.

2 Se estima que en México, anualmente ingresan o transitan por el país 250000 migrantes centro y sudamericanos

Se hace referencia a leyes federales, pues es facultad del Congreso de la Unión legislar sobre esta materia de acuerdo a la fracción XVI del artículo 73 de la Constitución Política de los Estados Unidos Mexicanos.

4 De acuerdo al artículo segundo del decreto publicado el 25 de mayo de 2011, se reforman los artículos 77, 81, 83 y 84; se derogan las fracciones VII y VIII del artículo 3o.; los artículos 7o. a 75, 78 al 80, 82, 113, fracciones II, III y V; artículos 116 al 118, 125 y 141 y 143 al 157 de la Ley General de Población, numerales que regían lo relativo a Migración, Inmigración, algunas cuestiones de Repatriación, sanciones por violaciones a las disposiciones 
dos y Protección Complementaria que se ocupa de las figuras de refugio y de protección complementaria, y que tiende a cumplir con algunos de los estándares internacionales contenidos en instrumentos internacionales en materia de protección humanitaria firmados y ratificados por el Estado mexicano como la Convención sobre el Estatuto de los Refugiados de 1951, ${ }^{5}$ y por último la expedición de la Ley de Migración que en un amplio sentido se ocupa de la movilidad internacional de personas.

En este artículo se analiza de manera especial la Ley de Migración promulgada en 2011, legislación que representa el esfuerzo por reunir en un único cuerpo normativo, todas las disposiciones relativas al fenómeno migratorio internacional, con el fin de simplificar y ordenar los procedimientos migratorios administrativos y así atender y gobernar eficientemente los diversos procesos migratorios que ocurren en el país; de establecer claramente las bases sobre las cuales se debe construir una política migratoria mexicana coherente; de ceñir la actuación de las autoridades, tanto migratorias como auxiliares, a reglas jurídicas claras y precisas que otorguen seguridad jurídica a los extranjeros en México y que garanticen el respeto irrestricto de los derechos humanos de los migrantes.

Por ello, el objetivo de este artículo es dar a conocer al lector las disposiciones jurídicas introducidas por la Ley de Migración y, a través de su análisis, determinar los efectos que las mismas podrían tener sobre la situación jurídica de los extranjeros en México; a ese efecto, en primer lugar haremos una breve descripción de la Ley en su totalidad; después, nos enfocaremos a las disposiciones que por su novedad o finalidad resultan relevantes; posteriormente, efectuaremos un análisis comparativo de las categorías contenidas en las disposiciones migratorias de la Ley General de Población y la Ley de Migración, y finalmente estaremos en posibilidad de realizar un balance sobre la pertinencia de esta recién publicada Ley de Migración.

migratorias, el procedimiento migratorio y el procedimiento de verificación y vigilancia, cuestiones todas estas reguladas ahora por la Ley de Migración.

Adoptado en Ginebra, Suiza el 28 de julio de 1951, al que México se adhirió el 7 de junio de 2000 y fue promulgada por decreto publicado en el Diario Oficial de la Federación el 25 de agosto de 2000 . 


\section{LEY DE MIGRACIÓN}

La Ley de Migración fue expedida mediante decreto publicado el 25 de mayo de 2011 en el Diario Oficial de la Federación, y junto con la Ley sobre Refugiados y Protección Complementaria, constituyen lo que podría denominarse el fundamento jurídico de la política migratoria del Estado mexicano para el siglo XXI; en efecto la ley que en esta oportunidad se comenta, tiene por objeto "regular lo relativo al ingreso y salida de mexicanos y extranjeros al territorio de los Estados Unidos Mexicanos y el tránsito y la estancia de los extranjeros en el mismo"; ${ }^{6}$ lo que la hace una ley especial en materia migratoria, que sustituye en ese aspecto a la Ley General de Población, el ordenamiento jurídico migratorio vigente en México desde 1974. En este apartado se ofrece un esbozo del contenido y estructura de la ley con la finalidad de ubicar las disposiciones a que habremos de referirnos en los siguientes capítulos.

La Ley de Migración se divide en ocho títulos. El primero, de las "Disposiciones preliminares", delimita el objeto de la ley, define la política migratoria del Estado mexicano como "el conjunto de decisiones estratégicas para alcanzar los objetivos determinados... para atender el fenómeno migratorio en México de manera integral, como país de origen, tránsito, destino y retorno de migrantes"7 y señala los principios sobre los que ésta debe descansar y que son: a) respeto irrestricto a los derechos humanos de los migrantes; b) congruencia del Estado mexicano al garantizar los derechos que reclama para sus nacionales en el exterior; c) el abordar el fenómeno desde un enfoque integral como corresponde a su complejidad; d) responsabilidad compartida, tanto con instituciones nacionales y extranjeras, como con gobiernos extranjeros; e) la hospitalidad y solidaridad internacionales; f) facilitación de la movilidad internacional de personas con orden y seguridad; g) la complementariedad de los mercados laborales en la región; $h$ ) la equidad entre nacionales y extranjeros al amparo del artículo 1o. de la Constitución Política de los Estados Unidos Mexicanos; i) el reconocimiento a los

Artículo 1o. de la Ley de Migración.

Artículo 2o. de la Ley de Migración. 
valores adquiridos de los migrantes; j) la unidad familiar y el interés superior de los menores de edad como principal criterio para autorizar la internación y estancia de extranjeros en el país; $k$ ) promoción de la integración social y cultural entre nacionales y extranjeros; l) simplificación del retorno y la reinserción social a los emigrantes mexicanos. Este título también otorga competencia para la aplicación de la ley a la Secretaría de Gobernación.

El título segundo por su parte, describe los derechos y las obligaciones de los migrantes, y la obligación del Estado mexicano de garantizar el trato igual a extranjeros con respecto a los nacionales, en el ejercicio de sus derechos, independientemente de su situación migratoria, como el acceso a los servicios educativos y a la atención médica, procuración e impartición de justicia, o la autorización y registro de los actos referentes a su estado civil, según los artículos 8o. a 11 de la ley; adicionalmente, establece la obligación de la autoridad de tomar en cuenta la edad de los niños, niñas y adolescentes migrantes, cuando sean ellos los involucrados en cualquier tipo de procedimiento que emana de esta ley.

El título tercero "De las autoridades en materia migratoria" establece las atribuciones de la Secretaría de Gobernación, del Instituto Nacional de Migración, la Secretaria de Relaciones Exteriores, y de otras autoridades auxiliares en el tema migratorio; lo que ofrece claridad sobre las funciones que cada una debe desempeñar en aras de una actuación eficiente y coordinada entre ellas. Cabe destacar que sobre la Secretaría de Gobernación recae la formulación y dirección de la Política Migratoria, mientras que su instrumentación la hace sobre el Instituto Nacional de Migración (INM) ${ }^{8}$ y a fin de tener una adecuada implementación de la misma con pleno respeto a los derechos humanos, se ha incluido un sistema de profesionalización y certificación de los servidores públicos adscritos al INM.

En el título cuarto "Del movimiento internacional de personas y la estancia de extranjeros en territorio nacional" se consignan los requisitos exigibles a los extranjeros para ingresar al país, con lo que se otorga certeza jurídica respecto de las decisiones de la autoridad de permitir o no su internación. Este título contiene una importante reforma al

\footnotetext{
8 Artículos 18 y 20 de la Ley de Migración.
} 
sistema migratorio vigente bajo la Ley General de Población, pues asigna nuevas categorías migratorias a las personas extranjeras en México; estas modificaciones serán tratadas en el capítulo siguiente.

Después, el título quinto habla de la protección a los migrantes que transitan por el territorio nacional con independencia de su situación migratoria y establece los derechos de los migrantes en situación irregular al momento de su presentación ante las autoridades; además prevé que la Secretaría de Gobernación celebre convenios de colaboración con los tres órdenes de gobierno, así como con dependencias y entidades de la administración pública federal con el objetivo de implementar acciones tendientes a coadyuvar con las organizaciones de la sociedad civil en auxilio de los migrantes, y de coordinarse con aquéllas en la prevención, persecución, combate y atención a los migrantes víctimas de delitos. ${ }^{9}$

El título sexto rige al "Procedimiento Administrativo Migratorio". Este título no sólo establece los lineamientos que seguirá el procedimiento, sino que impone la obligación de la autoridad de salvaguardar los derechos de los migrantes en el desarrollo del mismo, en el ejercicio de las funciones de control, revisión, verificación; alojamiento en estaciones migratorias; procedimientos de deportación, retorno asistido y presentación. Para ello se introducen plazos y garantías procesales de observancia obligatoria. Resulta novedosa la adecuación del procedimiento tratándose de personas en situación vulnerable como los menores de edad, mujeres embarazadas, adultos mayores o discapacitados.

Dentro del séptimo título se establecen las sanciones a que se harán acreedoras las personas que violen las disposiciones de la ley, ya sean físicas o morales, nacionales o extranjeras, y hace hincapié en las aplicables a los servidores públicos del Instituto Nacional de Migración.

Por último, el octavo título trata "De los delitos en materia migratoria”, en sus cuatro artículos se tipifican los delitos migratorios y se establecen las penas que les son aplicables. Los delitos que prevé esta ley son tres y se configurarán siempre que las siguientes acciones tengan por objeto o fin obtener directa o indirectamente un lucro:

9 Artículos 66, 69, 71, 72 y 75 de la Ley de Migración. 
- Llevar a una o más personas a internarse en otro país sin la documentación correspondiente.

- Introducir, sin la documentación correspondiente, a uno o varios extranjeros a territorio mexicano.

- Albergar o transportar por el territorio nacional a uno o varios extranjeros con el fin de evadir la revisión migratoria.

Las conductas que esta ley tipifica como delito, coinciden con las acciones que durante años han llevado a cabo las personas conocidas popularmente como "polleros", mismos que incluso han llegado a cobrar más de cinco mil dólares americanos, ${ }^{10}$ a cambio de llevar a una persona a internarse a los Estados Unidos de América sin la documentación correspondiente, a riesgo de su vida y de su integridad física y que por su falta de documentación migratoria son presa fácil de la delincuencia organizada y en algunos casos de la actuación arbitraria e ilegal de las autoridades tanto mexicanas como estadounidenses.

Lo descrito hasta aquí proporciona una idea general del contenido de la Ley de Migración; ahora, en las siguientes secciones nos ocuparemos de hacer énfasis en las cuestiones relevantes de la ley que se comenta.

\section{DiSPOSICIONES RELEVANTES}

El contenido de la ley resulta interesante y novedoso no sólo por su lenguaje y extensión, sino por el contenido relevante, a nuestro criterio, de

10 Esta actividad ilegal, ahora delictuosa en México, genera ganancias anuales de apróximadamente 6.6 mil millones de dólares de acuerdo con Antonio Mazzitelli, representante de la Oficina Regional de las Naciones Unidas contra la Droga y el Delito (UNODC) para México, Centroamérica y el Caribe de la Organización de las Naciones Unidas, quien dijo que México está considerado como puente, tránsito y destino para la trata de personas para la explotación sexual, comercial y trabajo forzado, estos datos explican por sí mismos la necesidad de tipificar como delito las acciones que se comentan. Sosa, Miguel y Gutiérrez, Oscar, "Polleros ganan 6.6 mil mdd:ONU. Movilizar a migrantes más redituable que narco, afirma”, El Universal online, visible en www.eluniversal.com.mx/nacion/184424.html, 29 de marzo de 2011, consultado el 9 de abril de 2011. 
algunas de sus disposiciones que ahora se analizan; además sistematiza las disposiciones migratorias, lo que facilita su localización y consulta.

\section{Derechos de los migrantes}

Por primera vez, se consignan expresamente dentro del cuerpo legal, los principios que regirán la política migratoria nacional, que incluyen y desarrollan los seis principios fundamentales que sustentan la propuesta de la Comisión Mundial sobre Migraciones Internacionales de la Organización de las Naciones Unidas, para la creación de un marco global, coherente y mundial de acción sobre migración, y que los hizo consistir en:

1) El papel de los migrantes en un mercado de trabajo mundial.

2) Las migraciones y el desarrollo.

3) Las migraciones irregulares.

4) Los migrantes en la sociedad.

5) Los derechos humanos de los migrantes.

6) La gobernabilidad de las migraciones. ${ }^{11}$

Al amparo de este propósito del Estado mexicano (expresado también en Plan Nacional de Desarrollo vigente), de incorporar y cumplir con sus compromisos jurídicos internacionales, se pretende hacer efectivo a través de esta ley, el reconocimiento de derechos a los migrantes, independientemente de su situación migratoria, que no es otra cosa que la hipótesis en la que se ubica un extranjero, en función del cumplimiento o incumplimiento de las disposiciones migratorias para su internación y estancia en el país, de modo tal que si el migrante ha cumplido con las disposiciones migratorias respectivas para su internación y estancia en México, su situación migratoria será regular y si no ha cumplido con ellas, entonces será irregular. ${ }^{12}$ En consecuencia el migrante

11 Las migraciones en un mundo interdependiente: nuevas orientaciones para actuar. Informe de la Comisión Mundial Sobre las Migraciones Internacionales. ONU Octubre 2005. Consultable en http: //www.gcim.org/mm/File/Spanish(1).pdf.

12 De acuerdo a la fracción XXVII del artículo 3o. de la Ley de Migración que se comenta. 
cuya situación migratoria es irregular, se identifica con la figura a la que despectivamente se ha dado en llamar ilegal o indocumentado

La precisión anterior es necesaria para aquilatar la importancia de los preceptos que conforman el Título Segundo de la Ley, pues el primero de ellos, al decir que "El Estado mexicano garantizará el ejercicio de los derechos y libertades de los extranjeros reconocidos en la Constitución, en los tratados y convenios internacionales de los cuales sea parte el Estado mexicano y en las disposiciones jurídicas aplicables, con independencia de su situación migratoria”, ${ }^{13}$ elimina como requisito para ser sujeto de derechos la demostración de contar con una legal estancia en México, lo que promueve la equidad entre nacionales y extranjeros y entre éstos, sea regular o irregular su situación. Además, esta ley consigna la libertad de las personas para transitar en el territorio nacional, pues limita la obligación de comprobar su nacionalidad y situación sólo ante la "autoridad competente en los casos y bajo las circunstancias establecidas en la ley”, ${ }^{14}$ lo que de observarse, traerá como consecuencia el cese de: 1) las detenciones y diligencias arbitrarias, llevadas a cabo por autoridades policiales o de cualquier otra naturaleza distinta a la migratoria, sin facultades para ello, y 2) la discriminación de las personas por su mera apariencia, o por la simple sospecha de las autoridades de no poseer la nacionalidad mexicana o de estar en México en situación irregular.

La vigencia de estos artículos importan una limitante a las facultades discrecionales de las autoridades administrativas, en concordancia con la reforma a la Constitución Política de los Estados Unidos Mexicanos, que introduce el decreto publicado en el Diario Oficial de la Federación el 10 de junio de 2011, por el que se modifican, entre otros, el primer párrafo del artículo 33 constitucional, para quedar como sigue: "El Ejecutivo de la Unión, previa audiencia, podrá expulsar del territorio nacional a personas extranjeras con fundamento en la ley, la cual regulará el procedimiento administrativo, así como el lugar y tiempo que dure la detención”. ${ }^{15}$ Esta significativa restricción, al permitir la expulsión de

13 Artículo 6o. de la Ley de Migración.

14 Artículo 7o., segundo párrafo, de la Ley de Migración.

15 El artículo 33 de la Constitución Política de los Estados Unidos Mexicanos, vigente hasta el 10 de junio de 2011, establecía la facultad, otrora discrecional, de que gozaba el poder 
migrantes del territorio nacional, únicamente a través del desahogo del procedimiento administrativo previsto por la ley, ${ }^{16}$ en el que se observarán todas las formalidades del debido proceso, hará efectivos los derechos humanos de los migrantes y sus garantías de audiencia y debido proceso consagradas en el Título Primero de la Constitución Política de los Estados Unidos Mexicanos, pues su expulsión no quedará al juicio unilateral y subjetivo del Poder Ejecutivo.

Aparte de los derechos de tránsito y debido proceso, los migrantes, con independencia de su situación migratoria, podrán:

- Acceder a los servicios educativos, sean públicos o privados.

- Recibir atención médica, sea ésta provista por el sector público o privado, la que además será gratuita cuando resulte urgente y necesaria para la preservación de su vida.

- Obtener de los jueces u oficiales del Registro Civil, la autorización de los actos del estado civil en que sean parte y la expedición de las actas correspondientes, que versen sobre nacimiento, reconocimiento de hijos, matrimonio, divorcio o defunción.

- Preservar la unidad de su familia, para lo cual se autorizará la entrada al territorio de los familiares de los migrantes que pretendan ingresar o residan de manera regular en el país o que pretendan regularizar su estancia.

- Acceder a la procuración e impartición de justicia y presentar quejas en materia de derechos humanos.

- Recibir información sobre sus derechos y obligaciones, los requisitos para su admisión, permanencia y salida del país y sobre la posibilidad de solicitar el reconocimiento de refugiado, el otorgamiento de protección complementaria, el otorgamiento de asilo político y la determinación de apátrida.

Ejecutivo de la Unión de hacer abandonar el territorio nacional, inmediatamente y sin necesidad de juicio previo, a todo extranjero cuya permanencia juzgue inconveniente.

16 De acuerdo con el artículo 77 de la Ley de Migración, el procedimiento administrativo migratorio se regirá por las disposiciones contenidas en título Sexto de la ley, en el Reglamento y en las disposiciones administrativas de carácter general que llegue a emitir la Secretaría de Gobernación. A este procedimiento le serán aplicables de manera supletoria, las disposiciones de la Ley Federal de Procedimiento Administrativo. 
- Contar con intérprete o traductor cuando desconozca el español y manifestarse por escrito cuando sea sordo, en cualquier diligencia en que intervenga y especialmente si se inicia en su contra el procedimiento administrativo migratorio.

- Exigir de la autoridad judicial, que haya dictado sentencia condenatoria en su contra, información sobre los tratados y convenios internacionales en materia de traslado de reos.

- Obtener de la autoridad migratoria la documentación que acredite su situación migratoria regular, cuando satisfagan los requisitos legales exigibles. ${ }^{17}$

Lo notable de este catálogo de derechos consiste en que las disposiciones legales vigentes antes de la entrada en vigor de la Ley de Migración, ${ }^{18}$ exigían la comprobación de la legal estancia de los extranjeros en el país, como requisito indispensable para la realización de cualquier acto o trámite y guardaban silencio acerca del acceso a la educación, salud o procuración de justicia; lo que se veía reforzado con la prohibición expresa a las autoridades de autorizar o llevar a cabo cualquier acto donde interviniera un extranjero sin comprobar su legal estancia, la cual debía hacer constar en el instrumento respectivo, además del permiso especial que en los casos establecidos por la ley era necesario.

La Ley de Migración reúne en su artículo 16 las obligaciones exigibles a los migrantes, las cuales se limitan a la custodia y resguardo de la documentación que acredite su identidad y situación regular en el país; deber de mostrar dicha documentación a requerimiento de las autoridades migratorias y proporcionar la información y datos personales que les soliciten las autoridades mexicanas en el ámbito de sus atribuciones y competencia.

De estas obligaciones desprendemos el hecho de que únicamente las autoridades migratorias podrán requerir a los migrantes que muestren los documentos que acrediten su identidad y la situación que tienen en el país, lo que se complementa con la norma de que "sólo las autorida-

17 Este derecho se consagra en el artículo 58 de la Ley de Migración.

18 Me refiero a los ahora derogados artículos 67 a 70 de la Ley General de Población, los que serán abordados en el apartado siguiente donde se hará el estudio comparativo pertinente. 
des migratorias podrán retener la documentación que acredite la identidad o situación migratoria de los migrantes cuando existan elementos para presumir que son apócrifas". ${ }^{19}$

\section{Autonomía de la política migratoria}

La Secretaría de Gobernación es la principal autoridad en materia migratoria en México, su principal atribución es formular y dirigir la política migratoria del país. ${ }^{20}$ La Ley de Migración establece esta facultad expresa como consecuencia del desprendimiento de la cuestión migratoria de la Ley General de Población, pues la política migratoria se consideraba parte de la política de población, por ello es que entre las facultades que le otorga a esta secretaría de Estado la Ley Orgánica de la Administración Pública Federal, encontramos la de "formular y conducir la política de población, salvo lo relativo a colonización, asentamientos humanos y turismo". ${ }^{21}$ Para llevar a cabo la responsabilidad de formular y dirigir la política migratoria de México, la Secretaría de Gobernación debe tomar en cuenta las opiniones de las autoridades auxiliares, de los poderes Legislativo y Judicial de la Unión, de los gobiernos estatales y de la sociedad civil.

Ahora, el artículo que se comenta invita a hacer las siguientes reflexiones, la primera, a la que nos referimos en el párrafo anterior, podemos identificarla como el reconocimiento de la importancia que ha adquirido el fenómeno migratorio en el país y en la región, al considerar que se requiere de una política de Estado para su gestión, independiente de la política de población dentro de la cual estuvo siempre inserta. Otro punto importante, es la posibilidad que se otorga a los poderes de la Unión y a los gobiernos locales, de emitir una opinión para que sea tomada en cuenta al momento de formular y dirigir la po-

19 Artículo 17 de la Ley de Migración, en el que se establece también que las autoridades al retener la documentación dudosa deberán hacerlo inmediatamente del conocimiento de las autoridades competentes para que resuelvan lo conducente.

20 Artículo 18 de la Ley de Migración.

21 Según la fracción IV del artículo 27 de la Ley Orgánica de la Administración Pública Federal. Se hace notar que dentro de las facultades que le confiere la referida ley a la Secretaría de Gobernación, contenidas en las 32 fracciones del numeral citado, no se desprende ninguna referencia a la cuestión migratoria. 
lítica de migración, aunque se destaca que esa misma posibilidad se le concede a la sociedad civil, ${ }^{22}$ no obstante, no establece los mecanismos a través de los cuales ejercitar esa facultad, cuestión que probablemente sea subsanada por el Reglamento de la Ley.

\section{Retorno asistido}

Otra de las atribuciones legales de la Secretaría de Gobernación, consiste en promover y suscribir instrumentos internacionales en materia de retorno asistido tanto de mexicanos como de extranjeros, en coordinación con la Secretaría de Relaciones Exteriores, facultad de la que carecía esta dependencia antes de la promulgación de la Ley de Migración, que introdujo también la categoría de retorno asistido, que no es otra cosa que el "procedimiento por el que el Instituto Nacional de Migración hace abandonar el territorio nacional a un extranjero, remitiéndolo a su país de origen o de residencia habitual”, ${ }^{23}$ beneficio que, a diferencia de la deportación, puede ser solicitado por los migrantes en situación irregular que se encuentren a disposición del Instituto y que no cuenten con restricciones legales para abandonar el país, pero que no hayan incurrido en ninguna de las hipótesis que establecen las seis fracciones del artículo 144 de la Ley de Migración.

\section{El Instituto Nacional de Migración}

La naturaleza jurídica del Instituto Nacional de Migración, asignada por la Ley de Migración, es la de un órgano administrativo desconcentrado dependiente de la Secretaría de Gobernación, tiene por objeto: a) la ejecución, controlar y supervisar los actos realizados por las autoridades migratorias, y b) instrumentar la política migratoria, basándose en los lineamientos que de la misma establece la Secretaría de Gobernación. Por primera vez, la existencia del Instituto está prevista en ley, ya que

\footnotetext{
22 Suponemos que organizada, aunque la ley no lo especifica.

${ }^{23}$ Artículo 3o., fracción XXIV, sobre su tramitación y pormenores hablan los artículos 114 a 118 , todos de la Ley de Migración.
} 
anteriormente el Reglamento de la Ley General de Población se ocupaba de él, pero sin determinar su naturaleza jurídica, y le atribuía dos objetivos muy generales, y sus atribuciones se encontraban dispersas en varios numerales del propio reglamento, factores ambos, que han permitido una amplia discrecionalidad a sus funcionarios en el ejercicio de su cargo. Ahora, la Ley de Migración sistematiza sus atribuciones, de modo que las prevé un solo artículo, ${ }^{24}$ las cuales se reproducen aquí textualmente, pues ellas delimitan el campo de acción de las autoridades migratorias:

- Instrumentar la política en materia migratoria;

- Vigilar la entrada y salida de personas al territorio de los Estados Unidos Mexicanos y revisar su documentación;

- En los casos señalados en esta Ley, tramitar y resolver sobre la internación, estancia y salida del país de los extranjeros;

- Conocer, resolver y ejecutar la deportación o el retorno asistido de extranjeros, en los términos y condiciones establecidos en la presente Ley y en su Reglamento;

- Imponer las sanciones previstas por esta Ley y su Reglamento;

- Llevar y mantener actualizado el Registro Nacional de Extranjeros;

- Presentar en las estaciones migratorias o en los lugares habilitados para tal fin $^{25}$, a los extranjeros que lo ameriten conforme a las disposiciones de esta Ley, respetando en todo momento sus derechos humanos;

- Coordinar la operación de los grupos de atención a migrantes que se encuentren en territorio nacional;

- Proporcionar información contenida en las bases de datos de los distintos sistemas informáticos que administra, a las diversas instituciones de seguridad nacional que así lo soliciten, de conformidad con las disposiciones jurídicas aplicables, y

24 El artículo 20 de la Ley de Migración en sus diez fracciones.

25 Estos establecimientos deben alojar exclusivamente a los extranjeros sujetos al Procedimiento Migratorio Administrativo durante el tiempo en que se resuelva éste, por lo que necesariamente deben ser distintos a cárceles, prisiones u otro tipo de centros de detención. Ello se ajusta a los estándares establecidos por la Corte Interamericana de Derechos Humanos en la sentencia de 23 de noviembre de 2010 que resolvió de fondo el Caso Vélez Loor vs. Panamá 
- Las demás que le señale esta Ley, su Reglamento y demás disposiciones jurídicas aplicables.

La primera atribución que en este artículo se le otorga al Instituto, se desmenuza en las siguientes fracciones, pues la política migratoria se organiza y aplica al vigilar la entrada y salida de personas del territorio nacional, conocer sobre la internación, estancia y salida de extranjeros, al imponer sanciones por violación a las disposiciones migratorias, al llevar el Registro Nacional de Extranjeros, al administrar las estaciones migratorias y presentar y alojar en ellas a los extranjeros, al coordinar la asistencia a los migrantes e informar sobre las disposiciones migratorias. No pasamos por alto, que esta ley impone a las autoridades realizar todo lo anterior, siempre con respeto a los derechos humanos de los migrantes.

Se arroga también al Instituto Nacional de Migración, la carga de profesionalizar y certificar a su personal, de modo que su actividad se ciña invariablemente a los "principios de legalidad, objetividad, eficiencia, profesionalismo, honradez y respeto a los derechos humanos", ${ }^{26}$ para lo cual se prevé la creación del Centro de Evaluación cuya función consistirá principalmente en evaluar periódicamente a los empleados del Instituto y comunicar el resultado de tales evaluaciones; emitir los certificados que avalen la evaluación; contribuir a identificar factores de riesgo en la prestación de servicios migratorios que pudieren entorpecer su eficiencia, y a grandes rasgos, contribuir a la capacitación del personal con el objetivo de que respeten los principios mencionados.

La creación de esta instancia se interpreta como una respuesta del Estado mexicano a las severas imputaciones de corrupción e ineficiencia que pesan sobre el Instituto, mismas que se han agravado en los últimos dos años, en los que varias organizaciones de la sociedad civil, tanto nacionales como internacionales, gobiernos estatales, gobiernos extranjeros, organizaciones internacionales e incluso particulares han denunciado la participación de las autoridades en la comisión de delitos, así como la realización de actos de extorsión, intimidación y en

26 Artículo 22 de la Ley de Migración. 
general, violatorios de derechos humanos, ${ }^{27}$ los que han sido difundidos en varios órganos informativos nacionales e internacionales.

De este modo, la Secretaría de Gobernación al diseñar, y el Instituto Nacional de Migración al instrumentar la política migratoria, son las autoridades principales en materia de migración, pues sobre ellas recae el diseño y la ejecución de toda su normatividad y gestión; aún así, requieren del auxilio, dentro del ámbito de su competencia, de otras instituciones y de los tres órdenes de gobierno, por ello la ley prevé y asigna funciones específicas a estas autoridades calificadas como auxiliares, las que son: la Secretaría de Relaciones Exteriores, la Secretaría de Turismo, la Procuraduría General de la República, el Sistema Nacional para el Desarrollo Integral de la Familia, y los sistemas estatales y del Distrito Federal para el Desarrollo Integral de la Familia.

\section{Condiciones de estancia en territorio nacional}

El título cuarto de la Ley de Migración, reviste gran importancia pues contiene las disposiciones que fijan los requisitos que deben cubrir los extranjeros para internarse y permanecer en territorio mexicano. Es aquí donde se fijan las categorías o condiciones de estancias que pueden ser otorgadas a las personas extranjeras en situación regular en México. En los primeros artículos del título, se prevé la facultad de la Secretaría de Gobernación de fijar, suprimir y cerrar temporalmente los lugares destinados al tránsito internacional de personas y las características que tendrán los mismos, dichos lugares son por los que exclusivamente se permitirá la internación y salida de personas del territorio nacional, así pues, para que la internación de un extranjero sea calificada como regular y por ende su situación en México también lo sea, debe verificarse

27 Acaso una de las más graves acusaciones que de este tipo se hicieron contra el Instituto Nacional de Migración, tuvo su origen con la nota periodística publicada el 24 de marzo de 2011 en varios medios en donde se denunció la persecución de una inmigrante hondureña por un agente de migración que, machete en mano, amenazaba su vida y la obligó a tirarse al río Usumacinta, en el municipio tabasqueño de Tenosique, para evadir el peligro que le significaba enfrentarse al agente. "Agente del INM persigue a Hondureña con machete”, El Universal online, disponible en www.eluniversal.com.mx/notas/754202.html, consultado el 9 de abril de 2011. 
con su paso a través de "los filtros de revisión migratoria ubicados en los lugares destinados al tránsito internacional de personas por tierra, mar y aire, dentro de los horarios establecidos para tal efecto y con intervención de las autoridades migratorias". ${ }^{28}$

De este modo, una persona que no posee la nacionalidad mexicana, por no reunir los requisitos del artículo 30 de la Constitución Política de los Estados Unidos Mexicanos, al internarse a territorio mexicano por los lugares destinados al tránsito internacional de personas, ${ }^{29}$ ya sea por tierra, mar o aire, debe pasar necesariamente por los filtros de revisión migratoria, dentro del horario establecido para ello y su paso debe realizarse con intervención de las autoridades migratorias destacadas en tales puntos para el efecto de verificar su documentación e identidad, así como el cumplimiento de los requisitos legales para su internación ${ }^{30}$ y registrar su entrada, requisitos indispensable para considerar su internación y estancia como regular y como consecuencia asignársele o reconocerle una condición de estancia acorde a sus circunstancias particulares. Las mismas condiciones se deben verificar para salir del territorio nacional, además de demostrar su situación migratoria regular del país o en su defecto el permiso de salida correspondiente.

Aparte de contar con pasaporte o documento de identidad y viaje vigente y válido, los extranjeros que pretendan ingresar a México, cuando así se requiera, ${ }^{31}$ deben contar con visa vigente, la cual es otorgada por la Secretaría de Gobernación a través de sus oficinas establecidas en territorio nacional o en las representaciones consulares en el exterior. Es facultad de la misma secretaría negar la expedición de visa, la entrada o la permanencia de los extranjeros, aun cuando cumplan con los re-

\section{Artículo 34 de la Ley de Migración}

29 El lugar destinado al tránsito internacional de personas consiste en el espacio físico fijado por la Secretaría de Gobernación para el paso de personas de un país a otro, de acuerdo a la fracción XV del artículo 3o. de la Ley de Migración.

30 Los documentos que un extranjero debe presentar en el filtro de revisión migratoria ante el personal del Instituto Nacional de Migración son: pasaporte o documento de identidad y viaje válido conforme al derecho internacional, visa vigente, en caso de ser necesaria o tarjeta de residencia o autorización otorgada por el Instituto Nacional de Migración. Además deberán proporcionar la información y datos personales o estadísticos que se les requiera.

31 Este requisito no es necesario para los extranjeros que: a) son nacionales de países con los que se haya suscrito un acuerdo de supresión de visa. 
quisitos legales o reglamentarios, cuando se encuentren dentro de las hipótesis que marca el artículo 43 de la Ley de Migración

Ahora bien, las condiciones de estancia que el derecho mexicano otorga a los extranjeros son las de a) visitante, que puede ser con o sin permiso para realizar actividades remuneradas, visitante regional, trabajador fronterizo, por razones humanitarias o con fines de adopción; b) residente temporal o residente temporal estudiante, y c) residente permanente.

Esta clasificación legal es limitativa y el otorgamiento de cada una de las condiciones de estancia está sujeto a que el extranjero cumpla con los requisitos exigidos en la propia ley y en su reglamento, siempre y cuando a juicio de la Secretaría no se actualicen las hipótesis a que se refiere el artículo 43 de la ley, arriba citado.

Las condiciones de residente temporal, residente temporal estudiante y residente permanente conceden a sus titulares el derecho a la preservación de la unidad familiar, lo que se traduce en la posibilidad de solicitar a su ingreso o posteriormente el ingreso de sus padres, hijos menores de edad, cónyuge, concubina o concubinario y, tratándose de residente permanente, los hermanos menores de edad o de los que ejerza su representación legal. Este derecho lo tienen también los mexicanos.

Para obtener la condición de residente permanente, que ofrece la ventaja de contar con una duración indefinida, por regla general los residentes temporales deberán cumplir con una estancia previa de cuatro años; no obstante, la Ley de Migración introduce un novedoso mecanismo para obtener dicha condición, denominado "sistema de puntos", ${ }^{32}$ dentro del cual se tomarán en cuenta las capacidades del extranjero, de acuerdo a su nivel de instrucción, aptitudes o experiencia laboral. Este sistema beneficiará a las personas que por sus aptitudes se consideren benéficas para el país y que deseen residir definitivamente en México.

32 La creación de ese sistema se prevé en el artículo 57 de la Ley de Migración, aunque su mecanismo será implementado por disposiciones administrativas de carácter general que publicará la Secretaría de Gobernación en el Diario Oficial de la Federación. 


\section{Protección a los migrantes dentro del territorio nacional}

La afirmación legal: "El Estado mexicano garantizará el derecho a la seguridad personal de los migrantes, con independencia de su situación migratoria", ${ }^{33}$ arroja una pesada carga sobre las autoridades nacionales. Durante los años 2010 y 2011 los medios informativos han publicado prácticamente a diario notas relacionadas con delitos cometidos contra los migrantes en situación irregular, tales como secuestro, explotación laboral o sexual, lesiones y homicidio. Esos hechos han sido denunciados y condenados ${ }^{34}$ por organizaciones de la sociedad civil nacionales e internacionales, la Iglesia católica, la Comisión Nacional de Derechos Humanos, algunos gobiernos centroamericanos cuyos nacionales se han visto directamente afectados e incluso por autoridades nacionales, de los tres órganos de gobierno, siendo uno de estos desafortunados acontecimientos la matanza del 25 de agosto de 2010, de más de setenta migrantes en el ejido El Huizachal, perteneciente al municipio de San Fernando, Tamaulipas. ${ }^{35}$

33 Segundo párrafo del artículo 66 de la Ley de Migración.

34 De acuerdo a Amnistía Internacional, en México se vive una crisis de derechos humanos cuya principal víctima son los migrantes indocumentados, según lo dio a conocer en la nota PRE01/136/2010 del 28 de abril de 2010, Los abusos generalizados contra migrantes en México son una crisis de derechos humanos, disponible en www.amnesty.org/es/for-media/press-releases/ mexico-los-abusos-contra-migrantes-crisis-de-ddhh-2010-04-28/, consultado el 23 de mayo de 2011.

Según la Comisión Nacional de Derechos Humanos, en 2010, 20000 migrantes centro y sudamericanos fueron secuestrados en México por bandas del crimen organizado que los extorsionan y los obligan a unirse a sus filas, información que dio a conocer a través de la nota Identifica la CNDH 71 municipios de riesgos para inmigrantes, en Excelsior online, disponible en www.excelsior.com.mx/index.php? $m=$ nota\&id_nota $=730784$, consultado el 15 de junio de 2011.

En el mismo tenor, la arquidiócesis primada de México en una nota publicada en su semanario Desde la Fe, el 3 de abril de 2011, afirmó “... que las autoridades mexicanas no sólo han hecho poco por salvaguardar la dignidad e integridad de los migrantes, sino que no hay una intención clara de buscar un acuerdo con el vecino país del norte para hacer realidad una reforma migratoria integral", Ofenden ganancias por tráfico de migrantes: Iglesia Católica, en www. eluniversal.com.mx/notas/756442.html, consultado el 9 de abril de 2011.

35 Aranda, Jesús, "Zetas ejecutaron por la espalda a 72 migrantes; no pudieron pagar rescate”, La Jornada online, disponible en www.jornada.unam.mx/2010/08/26/política/002n1pol, consultado el 23 de mayo de 2011. 
En este sentido, la Ley de Migración al imponer la obligación que se comenta al Estado, reconoce la facultad de los migrantes de ejercer sus derechos y libertades, dentro del territorio nacional independientemente de su situación migratoria, como ya se dijo

Esta ley otorga al migrante en situación irregular la seguridad de que será tratado sin discriminación alguna ni será víctima de arbitrariedades por parte de la autoridad migratoria pues será sometido al procedimiento administrativo migratorio, el cual se desarrollará con estricto apego a la legalidad y durante el cual contará con la asistencia de la persona que él designe, además de que será informado oportunamente sobre sus derechos procesales, la legislación aplicable, el motivo de su presentación, los requisitos para la regularización de su situación migratoria y la notificación que ésta haga a la representación consular del país del que sea nacional a fin de que pueda acogerse a su protección. ${ }^{36}$ Este procedimiento incluye la presentación, el alojamiento en las estaciones migratorias, el retorno asistido y la deportación.

Adicionalmente, la Secretaría de Gobernación creará grupos de protección y defensa de los migrantes, para lo que podrá celebrar convenios de colaboración con las dependencias y entidades de la administración pública federal, los estados y los municipios, así como con la sociedad civil para un óptimo y eficaz funcionamiento de los mismos.

Este procedimiento administrativo podrá ser de control, verificación y regulación migratoria, el control migratorio consiste en revisar la documentación de personas que pretenden internarse o salir del país, así como la inspección de los medios de transporte utilizados para tal fin. La verificación consiste en la realización de visitas por parte del Instituto Nacional de Migración con la finalidad de comprobar el cumplimiento de las obligaciones de los extranjeros en México.

Además del control y la verificación migratoria, la autoridad cuenta con la figura de la revisión, la que se llevará a cabo en los lugares destinados al tránsito internacional de personas y dentro del territorio

36 Esta notificación se ajusta lo manifestado por la Corte Interamericana de Derechos Humanos en su opinión consultiva acerca de El Derecho a la Información sobre la Asistencia Consular en el Marco de las Garantías de Debido Proceso Legal, y la interpretación que en ella hace de los apartados b y c del artículo 36.1 de la Convención de Viena sobre Relaciones Consulares. 
nacional a fin de comprobar la situación migratoria (regular o irregular) de los extranjeros. Esta ley introduce la obligación expresa de que el acto que ordene la revisión deberá contar con los requisitos que establece el artículo 38 de la Ley Federal de Procedimiento Administrativo, lo que en materia migratoria constituye una novedad pues antes de la reforma al artículo 33 de la Constitución Política de los Estados Unidos Mexicanos, las diligencias migratorias e inclusive la expulsión de los extranjeros no tenían limitación legal pues eran ejercitadas al amparo de las facultades discrecionales del Poder Ejecutivo.

\section{Personas en situación de vulnerabilidad}

Por último, la circunstancia de que en la Ley de Migración, se prevean tratamientos excepcionales en el desahogo de cualquier procedimiento administrativo migratorio, en el alojamiento en las estaciones migratorias, en el control migratorio al momento de entrar o salir del territorio nacional y en el ejercicio de los derechos y libertades que esta ley, la Constitución Política de los Estados Unidos Mexicanos y los tratados internacionales reconocen a los migrantes, a los menores de edad no acompañados, mujeres embarazadas o con hijos lactantes y personas de la tercera edad, constituye una novedad respecto a cualquier disposición jurídica migratoria que haya tenido vigencia anteriormente, tales beneficios van desde resguardarlos bajo la custodia del Instituto Nacional de Migración; tratándose de alojamiento, se les proporcionará un espacio separado del que ocupan los adultos y los varones e incluso, se les prescribirá una dieta especial que responda de manera adecuada a sus necesidades de nutrición. ${ }^{37}$

La realidad es que no hay espacio suficiente dentro de las cuarenta y siete estaciones migratorias existentes en el país, ${ }^{38}$ para alojar a todos los migrantes que por violación a las disposiciones jurídicas aplicables hayan sido sancionados con esa medida, por lo que se antoja, al menos de momento, imposible contar con el espacio suficiente para cumplir

37 Artículo 107, fracción II de la Ley de Migración.

38 Que en conjunto cuentan con capacidad para albergar a 4000 personas. 
con los preceptos legales que plantean un alojamiento especial, al menos en el caso de las mujeres embarazadas o con hijos lactantes y de las personas de la tercera edad, pues si se trata de los menores de edad, la fracción I del artículo 112, ordena que su custodia y alojamiento será a cargo del Sistema Nacional, de los estados o del Distrito Federal para el Desarrollo Integral de la Familia en los centros administrados por ellos para fines de custodia, aunque tampoco se ha anunciado que el sistema haya adquirido o habilitado inmueble alguno para tal fin.

\section{Participación de la sociedad civil}

Merece mención dentro de esta sección, un pequeño párrafo inserto en el artículo 159 de la Ley de Migración, en el título octavo donde se legisla sobre los delitos migratorios. Este párrafo establece:

No se impondrá pena a las personas de reconocida solvencia moral, que por razones estrictamente humanitarias y sin buscar beneficio alguno, presten ayuda a la persona que se ha internado en el país de manera irregular, aun cuando reciban donativos o recursos para la continuación de su labor humanitaria.

Este artículo es innovador. En primer lugar porque exenta de pena a las personas de vocación humanitaria que auxilien a los migrantes irregulares, y en segundo lugar porque reconoce la labor de la sociedad civil, pues al decir personas se refiere a aquéllas de carácter privado, distintas de las autoridades, además no distingue entre personas físicas y morales; lo que nos lleva a interpretar este párrafo como incentivo a la actividad protectora de los migrantes, pues éstos son víctimas de la delincuencia y en ocasiones, las personas no les ofrecen ayuda por temor a ser sancionadas por el Estado. Por supuesto, no soslayamos que para que se actualice lo aquí sancionado, deben agotarse los tres requisitos que impone, a saber: contar con reconocida solvencia moral, realizar esta actividad con fines estrictamente humanitarios y no buscar beneficios personales pecuniarios ni de otra índole. 


\section{ANÁLISIS COMPARATIVO CON LA LEY GENERAL DE POBLACIÓN}

En el apartado anterior ofrecemos una visión sobre los conceptos notables introducidos por la Ley de Migración, dada su novedad y la circunstancia de que contiene más disposiciones que las conducentes de la Ley General de Población, el análisis entre ambas legislaciones se centrará en las categorías bajo las cuales los extranjeros o migrantes pueden internarse y permanecer en territorio mexicano.

La situación migratoria irregular de las personas en México, se actualiza del mismo modo en ambas legislaciones, al verificarse el incumplimiento de los requisitos legales que establecen para el ingreso y permanencia de los extranjeros.

En cuanto a la situación regular, la ley General de Población contemplaba que los extranjeros sólo podían internarse a México bajo las calidades de No Inmigrante e Inmigrante ${ }^{39}$; también que dentro del territorio podían obtener las calidades migratorias de no inmigrante, inmigrante o inmigrado.

Las personas a quienes se les otorgaba la calidad de no inmigrante, eran quienes se internaban temporalmente al país y podían poseer las características de turista, transmigrante, visitante, ministro de culto o asociado religioso, asilado político, refugiado, estudiante, visitante distinguido, visitantes locales, visitante provisional y corresponsal.

Por su parte, según la Ley General de Población, el inmigrante se internaba legalmente en el país con el propósito de radicarse en él, en tanto adquiría la calidad de inmigrado. Y podía presentar, de acuerdo a las actividades que realizara en el país, las características de rentista, inversionista, profesional, cargo de confianza, científico, técnico, familiar, artista y deportista o asimilado.

En esa misma legislación, la calidad de inmigrado podía ser conferida al extranjero que ha adquirido derechos de residencia definitiva en el país. Esas calidades y características migratorias eran limitativas por lo que todas las personas que se internaran, sea con la finalidad de establecerse o únicamente transitar por el territorio nacional, sin que el

39 Articulo 41 de la Ley General de Población. 
gobierno federal le reconociera la titularidad de alguna de las calidades mencionadas, se encontraban en una situación de irregularidad.

En el capítulo anterior hemos referido ya cómo en la Ley de Migración se clasifica las categorías o condiciones de estancia de los extranjeros en México, lo interesante aquí es saber de qué manera se asignarán estas condiciones a las personas ya residentes en México, pues como ya comentamos también, uno de los derechos que le reconoce la Ley de Migración a los extranjeros es el respeto a los derechos adquiridos, de residencia en este caso. El siguiente cuadro ilustra las equivalencias entre calidades migratorias y condiciones de estancia:

\begin{tabular}{|c|c|}
\hline Ley General de Población & $\begin{array}{c}\text { Ley de Migración } \\
\text { (vigente a partir del } 26 \text { de mayo de 2011) }\end{array}$ \\
\hline $\begin{array}{l}\text { No inmigrante: } \\
\text { a) turista } \\
\text { b) transmigrante } \\
\text { c) visitante en todas sus modalidades a } \\
\text { excepción de ministro de culto, visitante } \\
\text { distinguido, visitante provisional y corres- } \\
\text { ponsal. }\end{array}$ & $\begin{array}{l}\text { Visitante sin permiso para realizar } \\
\text { actividades remuneradas. }\end{array}$ \\
\hline No inmigrante visitante local & Visitante regional \\
\hline No inmigrante estudiante & Residente temporal estudiante \\
\hline No inmigrante asilado político y refugiado* & Residente permanente \\
\hline $\begin{array}{l}\text { Inmigrante: } \\
\text { a) rentista } \\
\text { b) inversionista } \\
\text { c) profesional } \\
\text { d) cargo de confianza } \\
\text { e) científico } \\
\text { f) técnico } \\
\text { g) familiar } \\
\text { h) artista y deportista } \\
\text { i) asimilado }\end{array}$ & Residente temporal \\
\hline Inmigrado & Residente permanente \\
\hline
\end{tabular}

* En caso de que haya obtenido la característica de Refugiado antes de la entrada en vigor de la Ley sobre Refugiados y Protección Complementaria el 28 de enero de 2011.

A partir de estas equiparaciones legales, advertimos que las mismas podrían causar algunas inconformidades a sus tenedores, quienes tienen que esperar hasta que sea publicado el Reglamento de la Ley para conocer los procedimientos para realizar el cambio de su estatus migratorio. 
Como se desprende del cuadro, el no inmigrante visitante en todas sus modalidades, con excepción de ministro de culto, visitante distinguido, visitante provisional y corresponsal, se equiparará al visitante sin permiso para realizar actividades remuneradas; ahora bien, una de las modalidades del no inmigrante visitante, de acuerdo a la Ley General de Población y su Reglamento, autorizaba a su titular a realizar actividades lucrativas, era ésta la única característica migratoria que permitía al no inmigrante, trabajar a cambio de una remuneración, por ello, la Ley de Migración al entrar en vigor, impediría a estas personas a continuar con el desarrollo de una actividad remunerada, y las obligaría a cambiar de condición de estancia a la de visitante con permiso para realizar actividades remuneradas, lo que en la práctica se traduce en realizar trámites, erogaciones, y en algunos casos hasta pérdida o suspensión de su empleo, pues es obligación legal de los patrones, contratar extranjeros únicamente si éstos cuentan con el permiso correspondiente.

Ahora bien, la Ley de Migración no establece equivalencia para la calidad de no inmigrante con las características de ministro de culto, visitante distinguido, visitante provisional y corresponsal, por lo que los extranjeros que al amparo de la Ley General de Población ostentaban tal calidad y características se encuentran en una incertidumbre jurídica aun mayor al desconocer el estatus migratorio que les será reconocido a la entrada en vigor y operatividad de la Ley de Migración.

La calidad de Inmigrante era accesible para las personas que se internaban legalmente en el país con el propósito de radicarse en él, en tanto adquiere la calidad de inmigrado, ${ }^{40}$ se trataba de una situación que si bien no se consideraba permanente, sí otorgaba a su tenedor derechos de radicación, siendo uno de los más codiciados el que le permitía optar por la nacionalidad mexicana al poder obtener la "Carta de naturalización por residencia”, pues el principal requisito es ser extranjero que acredite una residencia en territorio nacional con la calidad migratoria de inmigrante o inmigrado cuando menos durante los últimos cinco años inmediatos anteriores a la fecha de solicitud, ${ }^{41}$ es decir, la Cancillería tomará como criterio para el trámite de este tipo de Carta de Natura-

\footnotetext{
40 Artículo 48 de la Ley General de Población.

${ }^{41}$ Dirección general de asuntos jurídicos de la Secretaría de Relaciones Exteriores, $w w w$. sre.gob.mx/index.php/carta-de-naturalizacion-por-residencia, consultada el 12 de junio de 2011.
} 
lización una residencia permanente, por ello podemos afirmar que esa secretaría de Estado sí considera como permanente la residencia del Inmigrante, y ahora, según la Ley de Migración, los inmigrantes serán considerados como residentes temporales, lo que hace inferir que al ser temporal su residencia, ésta no podrá tomarse en cuenta para acceder a la nacionalidad mexicana por naturalización.

Podemos sostener entonces, que uno de los apartados fundamentales de la ley, el de las condiciones de estancia, ha dejado de considerar algunas cuestiones fundamentales que intenta promover: el respeto los derechos adquiridos por los migrantes, al no precisar, en algunos casos, en qué hipótesis se encuentran ciertos extranjeros y en otros, al degradar en cierto sentido, la calidad jurídica que ostentan las personas.

\section{CONCLUSIONES}

La Ley de Migración ofrece novedades conceptuales, procedimentales y sustanciales. Introduce a nuestro derecho, figuras jurídicas que responden a la situación mundial actual y que obedecen en mayor parte a los compromisos jurídicos internacionales adquiridos por México, el más importante: el respeto a los derecho humanos; así, esta ley está inserta en la cadena de reformas legales y constitucionales publicadas en 2011.

La manera en que se introducen al texto legal, conceptos de derechos humanos de los migrantes, figuras inéditas como la del retorno asistido o el procedimiento administrativo migratorio, la necesidad de autonomía de la política migratoria, la naturaleza y atribuciones del Instituto Nacional de Migración, condiciones de estancia, mecanismos de protección a los migrantes, procedimientos y tratamientos especiales a las personas en situación de vulnerabilidad y el reconocimiento a la labor de la sociedad civil, ofrece la idea de que el gobierno federal se ocupa de satisfacer las demandas de la sociedad y de otros gobiernos sobre la materia migratoria al modernizar el marco jurídico que le permite la gestión y gobernabilidad de los diversos procesos migratorios que concurren en México.

En su conjunto, las disposiciones de la Ley de Migración, demuestran la primacía que ha ocupado la migración en la vida nacional, no sólo política, sino social y económica. 
Con todo, no afirmamos que esta legislación sea una especie de panacea a la conflictiva y difícil realidad migratoria del país, sobre todo si la misma no ha sido aplicada a la fecha en que esto se escribe; sin embargo, podemos afirmar que de su contenido, en contraste con la experiencia en el control, gestión y gobernabilidad de la migración bajo el marco jurídico que le antecede, concluimos que será benéfica y si bien no abarcará la totalidad del complejo fenómeno migratorio, sí proporcionará varias herramientas útiles a la autoridad y a los migrantes para sortear de mejor manera las vicisitudes inherentes al tránsito internacional de personas.

\section{BiBLIOGRAFÍA}

BAUBÖCK, Rainer, Transnational Citizenship; Membership and Rigths in International migration, Gran Bretraña, Edward Elgard, 2004.

Diccionario Jurídico Mexicano, México, UNAM, Instituto de Investigaciones Jurídicas, t. II, 1988.

GARCíA, Lila, "Desorden mundial, orden migratorio”, Boletín Mexicano de Derecho Comparado, núm. 124, enero-abril de 2009.

IbARRA MATEOS, Marcela (coord.), Migración: Reconfiguración transnacional y flujos de población, México, Universidad Iberoamericana Puebla, 2007.

SASSEN, Saskia, Globalization and its discontents, Nueva York, New Press, 1998.

\section{Legislación}

Constitución Política de los Estados Unidos Mexicanos.

Ley General de Población.

Ley de Migración.

Ley sobre Refugiados y Protección Complementaria.

Reglamento de la Ley General de Población.

Ley de Nacionalidad. 
Declaración Universal de Derechos Humanos.

Convención Interamericana de Derechos Humanos.

Opinión consultiva OC-18/03 de 17 de septiembre de 2003, solicitada por los Estados Unidos Mexicanos referente a la Condición Jurídica y Derechos de los Migrantes Indocumentados, emitida por la Corte Interamericana de Derechos Humanos.

Opinión consultiva OC-16/99 de 1 de octubre de 1999 solicitada por los Estados Unidos Mexicanos, sobre El Derecho a la Información sobre la Asistencia Consular en el Marco de las Garantías de Debido Proceso Legal, emitida por la Corte Interamericana de Derechos Humanos.

Caso Vélez-Loor VS. Panamá, sentencia de 23 de noviembre de 2010, dictada por la Corte Interamericana de Derechos Humanos.

\section{Fuentes electrónicas}

Las migraciones en un mundo interdependiente: nuevas orientaciones para actuar. Informe de la Comisión Mundial Sobre las Migraciones Internacionales. ONU Octubre 2005. Consultable en http://www. gcim.org/mm/File/Spanish(1).pdf

Informe del Relator Especial sobre los derechos humanos de los migrantes A/61/324 11 septiembre de 2006. Consultable en http:// daccessdds.un.org/doc/UNDOC/GEN/N06/517/85/PDF/N0651785. pdf? OpenElement.

Plan Nacional de Desarrollo 2007-2012. Consultable en http: / pnd.calderon.presidencia.gob. $\mathrm{mx}_{\mathrm{I}} /$.

Revista Internacional de Filosofía Jurídica, t. 27, julio de 2006. Consultable en http: / / www.ifs.csic.es/prensa /velasc13.pdf.

Alto Comisionado de las Naciones Unidas para los Refugiados. Consultable en http: / / www.acnur.org/.

Lo local y lo global: La antropología de la globalización y del transnacionalismo. Kearney M. Departamento de Antropología. Universidad de California, Riverside, California. Consultable en http://docencia. izt.uam.mx/feder/lectura\%2004\%20(Kearney).pdf. 
Secretaría de Relaciones Exteriores, www.sre.gob.mx.

Secretaría de Gobernación, www.segob.gob.mx.

El Universal online, www.eluniversal.com.mx.

Excelsior online, www.excelsior.com.mx.

Amnistía Internacional, www.amnesty.org/es. 